\title{
SFA intake among Japanese schoolchildren: current status and possible intervention to prevent excess intake
}

\author{
Keiko Asakura ${ }^{1,2, *}$ and Satoshi Sasaki ${ }^{2}$ \\ 'Department of Environmental and Occupational Health, School of Medicine, Toho University, 5-21-16 Omori-Nishi, \\ Ota-ku, Tokyo 143-8540, Japan: ${ }^{2}$ Department of Social and Preventive Epidemiology, School of Public Health, The \\ University of Tokyo, Tokyo, Japan
}

Submitted 27 April 2017: Final revision received 17 July 2017: Accepted 14 August 2017: First published online 9 October 2017

\begin{abstract}
Objective: Although a high intake of fat, particularly SFA, is a well-known risk factor for CVD, fat intake in Japan has attracted relatively little attention from health professionals to date due to the low intake in the Japanese population. However, recent surveys have shown an increase in fat intake in younger Japanese populations. Here, we described the fat intake and dietary sources of SFA in Japanese schoolchildren. Also, we experimentally exchanged a high-SFA food with a low-SFA substitute in the data, and calculated the resulting changes in nutrient intakes.

Design: The study was conducted nationwide under a cross-sectional design. A non-consecutive, three-day diet record was performed on two school days and a non-school day.

Setting: Fourteen elementary and thirteen junior high schools.

Subjects: Elementary-school children ( $n$ 629) and junior high-school children (n 281).

Results: Prevalence of excess fat intake was 35.4\% in boys and $45.0 \%$ in girls. Excess SFA intake was suspected in $97.7 \%$ of boys and $99.4 \%$ of girls when the dietary reference intake values for adults were applied. Major dietary sources of SFA were meat $(26.4 \%$ of total SFA intake), dairy products $(25.7 \%)$ and confectioneries $(11 \cdot 3 \%)$.

Conclusions: Since one-third to nearly one-half of our Japanese schoolchildren consumed excess fat, careful monitoring of fat intake in the Japanese population should be continued. Adoption of low-fat milk and/or lean meat in daily meals might be a suitable means of reducing fat, particularly SFA intake, in schoolchildren.
\end{abstract}

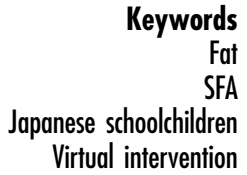

Higher intake of SFA has been associated with higher serum total and LDL cholesterol concentrations ${ }^{(1-3)}$ and higher risk of $\mathrm{CVD}^{(4,5)}$. SFA are not essential fatty acids and minimization of intake as low as possible is preferable for good health ${ }^{(6,7)}$. Since extreme restriction of SFA intake can cause insufficiencies in other nutrients such as protein or essential fatty acids, however, dietary recommendations or guidelines in several countries set maximum SFA intake at around $10 \%$ of energy (E\%). However, SFA intake in most Western countries is higher than the recommended values in both adults and children ${ }^{(6,8,9)}$.

Fat intake in Japan has so far attracted relatively little attention from health professionals. The fat content of traditional Japanese dishes is generally low, and the mean fat intake in the Japanese population of $26.3 \mathrm{E} \%$ in $2014^{(10)}$ is within the range (20-30 E\%) of 'the tentative dietary goal for preventing life-style related diseases (DG)' for total fat in the Dietary Reference Intakes (DRI) for Japanese, $2015^{(11)}$. With regard to SFA, the DG has been set at $\leq 7 \mathrm{E} \%$ for adults, but no reference value has been set for children due to a lack of SFA intake data ${ }^{(11)}$. Nevertheless, the National Health and Nutrition Survey in Japan showed that fat intake in young generations was much higher than that in older people in Japan. The proportion of adults whose fat intake in 2014 was more than $30 \mathrm{E} \%$ was $49.7 \%$ in people in their 20 s, but only $15 \cdot 8 \%$ in those in their 70 s or older ${ }^{(10)}$. With traditional diets changing to more Westernized diets, fat intake among the Japanese population may continue to increase with time. In addition, heart disease has become the second-leading cause of death in Japan, with mortality of 156.5 per 100000 individuals in $2015^{(12)}$. Given reports that dietary habits established in childhood track into later life ${ }^{(13)}$, this increasing fat intake in younger Japanese warrants careful observation. 
We had the opportunity to conduct a nationwide dietary assessment among Japanese schoolchildren ${ }^{(14)}$. Here, we utilized these data to describe fat intake and dietary sources of SFA in Japanese elementary-school and junior high-school children in detail. In addition, we experimentally exchanged a high-SFA food with a low-SFA substitute (e.g. full-fat milk to low-fat milk) in the data, and calculated the resulting changes in nutrient intakes.

\section{Methods}

\section{Study participants}

Details of the study design and participant characteristics have been reported elsewhere ${ }^{(14)}$. Briefly, twelve prefectures (Aomori, Yamagata, Ibaraki, Tochigi, Toyama, Shiga, Shimane, Ehime, Kochi, Fukuoka, Saga and Kagoshima) were chosen as study areas in consideration of geographical conditions (e.g. north or south, rural or urban) and study feasibility. From each area, ninety children (thirty children in each of third and fifth grade of elementary school and thirty children in second grade of junior high school) on average were recruited by teachers in the schools. All children in classes selected for the survey received a written document to explain the survey and recording sheets for the diet record. Finally, a total of 1190 children (389 third and 392 fifth graders from fourteen elementary schools and 409 second graders from thirteen junior high schools) were recruited.

\section{Semi-weighed diet record}

In the present study, dietary intake of the subjects was assessed by diet record (DR) at home and school, and their weight and height were measured at school ${ }^{(14)}$. Each school set the period for the non-consecutive, three-day DR and conducted the measurement of height and weight within one month of that period. All records were collected by the study centre at the university of the researchers and checked by the researchers. The dietitians or teachers who managed the survey at each school had a correspondence table which linked the children's names and identification numbers for the survey, but the researchers did not have access to this information.

Details of the semi-weighed DR have been provided elsewhere $^{(14)}$. Briefly, guardians of the participating children were asked to complete a three-day, non-consecutive DR of their children's dietary intake, of whom 915 complied (participation rate: $76.9 \%$ ). The three recording days for the DR consisted of two school days with a school lunch and one weekend day without a school lunch, all within the same week (e.g. Tuesday, Thursday and Saturday within one week).

Dietary intake from the school lunch was weighed and recorded by the school dietitian or the child under the dietitian's support. Dietary intake at home was recorded by the guardian who was the main preparer of meals for the participating child. All foods and beverages consumed out of school were recorded on the same two days set for the school lunch survey as well as on the one weekend (non-school) day. The guardians weighed the ingredients in dishes, the prepared dishes after cooking and all drinks, whenever possible. Leftover food was also weighed after the meal to estimate the net weight of consumed foods. If subjects ate out and weighing was difficult, they recorded the restaurant's name, names of dishes and whether any food was left uneaten.

The recording sheets for each survey day were handed directly to the school dietitian immediately after recording, then checked by the school dietitian as soon as possible. If missing or unclear information was recorded by a subject, the research dietitian questioned the subject directly. After this confirmation process, food item numbers ${ }^{(15)}$ were assigned to all recorded foods and beverages. Recorded food items and weights were then reconfirmed by two research dietitians at the central office of the study. The weight of each food and ingredient included in the school lunch was estimated at the office based on the weight of consumed dishes and conversion charts prepared by the school dietitians. The data for the lunch and the other meals were combined, and the nutrient values were calculated. All calculations were performed with the statistical software package SAS version $9 \cdot 4$.

\section{Other measurements}

Body height and weight were measured to the nearest $0 \cdot 1 \mathrm{~cm}$ and $0 \cdot 1 \mathrm{~kg}$, respectively, with the child wearing light clothing and no shoes. The prevalence of obesity in the children was evaluated by percentage of excess weight, which was defined using the formula: [(actual weight - standard weight)/standard weight $] \times 100 \quad(\%)$. If percentage of excess weight was $\geq 20 \%$, the child was categorized as overweight, and if $\leq-20 \%$, he/she was categorized as underweight. The standard weight was calculated using age- and sex-specific formulas which included actual height and coefficients ${ }^{(16)}$.

\section{Statistical analysis}

Among the 915 children who completed the three-day DR, 910 were included in the analysis. Five children were eliminated from the analysis due to severe underreporting ${ }^{(14)}$. To compare the fat intakes reported in the DR and the corresponding DRI values ${ }^{(11)}$, we adjusted the reported fat intakes to the energy-adjusted intakes on the assumption that each subject consumed his/her estimated energy requirement (EER) rather than his/her reported energy $^{(14)}$. The calculation method was as follows: Energyadjusted nutrient intake (amount $/ \mathrm{d})=$ reported nutrient intake (amount $/ \mathrm{d}) \times$ EER $\quad(\mathrm{kcal} / \mathrm{d})] /[$ observed energy intake $(\mathrm{kcal} / \mathrm{d})]$. The EER for each child was calculated based on sex and age in days. Physical activity level was 
fixed to level II (moderate) ${ }^{(11)}$ in all participating children due to the absence of quantitative information about physical activity. Utilizing these energy-adjusted fat intakes of three days, we estimated the distribution of habitual intake of total fat and each fatty acid in this population by the best-power method using HabitDist, a software application developed to perform this $\operatorname{method}^{(17-19)}$. The medians and interquartile ranges were described separately by sex and grade. For total fat and SFA, the percentage of energy (E\%), i.e. the percentage of energy intake from total fat or SFA to total energy intake, was used for comparison with DRI values. The Japanese DRI give DG for total fat in children, but not for SFA ${ }^{(11)}$. We therefore tentatively applied the DG for SFA in adults to children ${ }^{(11)}$. Energy-adjusted intake levels outside the range of the corresponding DG were considered inadequate. For nutrients with an Adequate Intake, the prevalence of inadequacy was not calculated.

Next, the contributions of food groups as dietary SFA sources were explored. The definition of the food groups has been described elsewhere ${ }^{(20)}$. The contribution of each food group was calculated as follows: $\{[\mathrm{SFA}$ intake $(\mathrm{g})$ from each food group]/[daily total SFA intake (g)]\} $\times 100(\%)$. The means of percentages were shown separately by sex and grade, and those less than $1 \%$ were not shown.

Lastly, we experimentally exchanged a high-SFA food with a low-SFA substitute in the DR data, and estimated the resulting changes in nutrient intakes. The performed exchanges were:

1a. full-fat milk containing $3 \cdot 8 \%$ fat to low-fat milk containing $1.0 \%$ fat (food item numbers ${ }^{(15)}$ in the DR data: 13 001-13003 were replaced with 13 005);

1b. full-fat and low-fat milk to skimmed milk containing $0 \cdot 1 \%$ fat (food item numbers 13001-13003 and 13005 replaced with 13006);

2. meat with fat (i.e. fatty meat including subcutaneous, intermuscular and intramuscular fat) to lean meat (e.g. food item numbers 11004 and 11005 (beef chuck with all fat or subcutaneous fat, raw) replaced with 11006 (beef chuck, lean, raw)); and

3. deletion of confectioneries (food item numbers in the 15000 s consumed as 'snacks' were deleted from the DR data).

The nutritional value calculation was performed using SAS version 9.4 as described above. No energy adjustment was performed for this analysis because the intakes were compared within each subject. Energy, protein, total fat, SFA and PUFA intakes were described for all selected foods before and after the replacement by sex and grade separately. Other nutrients were chosen based on the dominance of contents in the foods and the prevalence of insufficiency among schoolchildren as clarified in a previous study ${ }^{(14)}$. Vitamin A and Ca for milk, thiamin and Fe for meat, and carbohydrate and salt for confectioneries were selected. Mean intakes before and after replacement were compared with the Wilcoxon signed-rank test. The prevalence of inadequacy was calculated for SFA intake by comparing the mean intake (E\%) with the DG value for SFA intake in adults ( $\leq 7 \mathrm{E} \%$ ). The mean intake used here differed from the habitual intake estimated by the bestpower method, and the distribution of the mean SFA intake was broader than that of the habitual intake. All analyses were performed using SAS version 9.4. Statistical tests were two-sided and $P$ values of $<0.05$ were considered statistically significant.

\section{Results}

Subject characteristics are shown in Table 1. Each grade and sex stratum included approximately 150 children. Energy-adjusted, habitual fat intake is described in Table 2. The prevalence of inadequacy for total fat intake was $35.4 \%$ in all boys and $45.0 \%$ in all girls. All instances of 'inadequacy' were 'excess intake' for total fat. Although the Japanese DRI do not provide reference values for SFA for children, we tentatively compared the SFA intake in children with the reference value (DG) for adults. The SFA intake of $97.7 \%$ of the boys and $99.4 \%$ of the girls was higher than the DG ( $\leq 7 \mathrm{E} \%)$.

Major dietary sources of SFA are listed in Table 3. The three major sources were meat (26.4\% of total SFA intake came from meats in all children), dairy products (25.7\%) and confectioneries (11.3\%). The contribution of dairy products and confectioneries to SFA intake was smaller in children in higher grades. Instead, the importance of meat as an SFA source increased with age, particularly in boys. The contribution of fish and shellfish was also larger in children in higher grades.

Estimated nutrient intakes before and after the replacement of SFA-rich foods in the data are shown in Table 4. When full-fat milk was exchanged with low-fat milk, medians of SFA intake decreased from more than $9 \mathrm{E} \%$ (9.0-9.6) to $7.7-8.2 \mathrm{E} \%$. This decrease was largest in the third graders. Protein and $\mathrm{Ca}$ intakes increased by this replacement, but vitamin A intake decreased. The prevalence of inadequacy was changed by the replacement from $53.0 \%$ to $45.4 \%$ for $\mathrm{Ca}$ and from $27.5 \%$ to $38.2 \%$ for vitamin $\mathrm{A}$ in the total population. If skimmed milk was used instead of full-fat milk, SFA intake decreased more (7.4-7.8 E \%) but $\mathrm{Ca}$ and vitamin $\mathrm{A}$ intakes decreased. The prevalence of inadequacy was increased by this replacement from $53.0 \%$ to $57.6 \%$ for $\mathrm{Ca}$ and from $27.5 \%$ to $46.5 \%$ for vitamin A. The replacement of meat with fat with lean meat also decreased SFA intake to $7 \cdot 9-8.8 \mathrm{E} \%$. The decrease in SFA intake by meat replacement was smaller than that of milk, particularly in elementary-school children, whereas the effects of these foods were similar in junior high-school children. The meat replacement also increased protein and Fe intakes. Deletion of confectioneries as snacks also decreased SFA intake but the decrease was smaller than 
Table 1 Characteristics schoolchildren $(n$ 910) from fourteen elementary and thirteen junior high schools in twelve prefectures of Japan, 2014

\begin{tabular}{|c|c|c|c|c|c|c|c|c|c|c|c|c|c|}
\hline \multirow[b]{4}{*}{ Variable } & \multirow[b]{4}{*}{ Category } & \multicolumn{6}{|c|}{ Boys } & \multicolumn{6}{|c|}{ Girls } \\
\hline & & \multicolumn{4}{|c|}{ Elementary school } & \multirow{2}{*}{\multicolumn{2}{|c|}{$\frac{\text { Junior high school }}{\begin{array}{c}\text { 2nd grade } \\
(n \text { 134 })\end{array}}$}} & \multicolumn{4}{|c|}{ Elementary school } & \multirow{2}{*}{\multicolumn{2}{|c|}{ 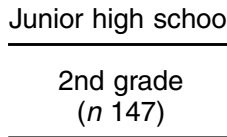 }} \\
\hline & & \multicolumn{2}{|c|}{$\begin{array}{c}\text { 3rd grade } \\
(n \text { 154) }\end{array}$} & \multicolumn{2}{|c|}{$\begin{array}{l}\text { 5th grade } \\
(n 144)\end{array}$} & & & \multicolumn{2}{|c|}{$\begin{array}{c}\text { 3rd grade } \\
\text { ( } n \text { 155) }\end{array}$} & \multicolumn{2}{|c|}{$\begin{array}{l}\text { 5th grade } \\
(n \text { 176) }\end{array}$} & & \\
\hline & & $\begin{array}{c}n \text { or } \\
\text { mean }\end{array}$ & $\begin{array}{c}\% \text { or } \\
\text { SD }\end{array}$ & $\begin{array}{c}n \text { or } \\
\text { mean }\end{array}$ & $\begin{array}{c}\% \text { or } \\
\text { SD }\end{array}$ & $\begin{array}{c}n \text { or } \\
\text { mean }\end{array}$ & $\begin{array}{c}\% \text { or } \\
\text { SD }\end{array}$ & $\begin{array}{c}n \text { or } \\
\text { mean }\end{array}$ & $\begin{array}{c}\% \text { or } \\
\text { SD }\end{array}$ & $\begin{array}{c}n \text { or } \\
\text { mean }\end{array}$ & $\begin{array}{c}\% \text { or } \\
\text { SD }\end{array}$ & $\begin{array}{c}n \text { or } \\
\text { mean }\end{array}$ & $\begin{array}{l}\% \text { or } \\
\text { SD }\end{array}$ \\
\hline \multirow[t]{6}{*}{ Age (years) } & 8 & 54 & $35 \cdot 1$ & 0 & 0.0 & 0 & 0.0 & 49 & 31.8 & 0 & 0.0 & 0 & 0.0 \\
\hline & 9 & 100 & 64.9 & 0 & 0.0 & 0 & 0.0 & 106 & $68 \cdot 8$ & 0 & 0.0 & 0 & 0.0 \\
\hline & 10 & 0 & 0.0 & 42 & $27 \cdot 3$ & 0 & 0.0 & 0 & 0.0 & 72 & $46 \cdot 8$ & 0 & 0.0 \\
\hline & 11 & 0 & 0.0 & 102 & $66 \cdot 2$ & 0 & 0.0 & 0 & 0.0 & 104 & 67.5 & 0 & 0.0 \\
\hline & 13 & 0 & 0.0 & 0 & $0 \cdot 0$ & 34 & $22 \cdot 1$ & 0 & 0.0 & 0 & $0 \cdot 0$ & 53 & $34 \cdot 4$ \\
\hline & 14 & 0 & 0.0 & 0 & 0.0 & 100 & 64.9 & 0 & 0.0 & 0 & 0.0 & 94 & $61 \cdot 0$ \\
\hline Height (cm) & Mean, SD & $131 \cdot 6$ & $5 \cdot 6$ & $143 \cdot 1$ & $6 \cdot 6$ & $163 \cdot 7$ & $7 \cdot 4$ & 131.0 & $5 \cdot 0$ & $144 \cdot 0$ & $6 \cdot 7$ & $156 \cdot 3$ & $5 \cdot 0$ \\
\hline Weight (kg) & Mean, SD & 29.7 & $6 \cdot 3$ & 37.6 & 8.6 & 54.8 & 11.6 & $28 \cdot 8$ & $5 \cdot 7$ & 37.5 & $8 \cdot 1$ & 48.9 & $7 \cdot 7$ \\
\hline \multirow{3}{*}{ Body constitution $†$} & Underweight & 3 & $2 \cdot 0$ & 4 & $2 \cdot 8$ & 2 & 1.5 & 2 & 1.3 & 4 & $2 \cdot 3$ & 8 & 5.4 \\
\hline & Normal & 134 & $87 \cdot 0$ & 121 & $84 \cdot 0$ & 115 & $85 \cdot 8$ & 133 & $85 \cdot 8$ & 153 & 86.9 & 131 & $89 \cdot 1$ \\
\hline & Overweight & 17 & 11.0 & 19 & $13 \cdot 2$ & 17 & $12 \cdot 7$ & 20 & $12 \cdot 9$ & 19 & $10 \cdot 8$ & 8 & 5.4 \\
\hline Energy intake $(\mathrm{kJ} / \mathrm{d})$ & Mean, sD & 8075 & 1234 & 9092 & 1460 & 11360 & 2360 & 7740 & 1197 & 8301 & 1314 & 9096 & 1724 \\
\hline Energy intake $(\mathrm{kcal} / \mathrm{d})$ & Mean, SD & 1930 & 295 & 2173 & 349 & 2715 & 564 & 1850 & 286 & 1984 & 314 & 2174 & 412 \\
\hline
\end{tabular}

Data are presented as $n$ and \% unless indicated otherwise.

†Body constitution was evaluated by percentage of excess weight, defined using the following formula: [(actual weight - standard weight)/standard weight] $\times$ $100(\%)$. If percentage of excess weight was $\geq 20 \%$, the child was categorized as overweight, and if $\leq-20 \%$, he/she was categorized as underweight.

those with the other replacements. Salt intake also decreased slightly with this replacement. Almost all intakes were statistically significantly different before and after replacement, but carbohydrate intake was not significantly changed by the deletion of confectioneries in boys. The prevalence of inadequacy for SFA intake is also shown in Table 4; although prevalence was lower than that calculated using the habitual intake shown in Table 3, owing to the broader distribution of the mean intake, the decrease in inadequate intake after replacement was obvious.

\section{Discussion}

One-third to nearly one-half of these Japanese schoolchildren consumed excess fat, and SFA intake in almost all of them was greater than the DG value ( $\leq 7 \mathrm{E} \%$ ) for Japanese adults. Major dietary sources of SFA were meat, dairy products and confectioneries. Adoption of low-fat milk and/or lean meat in daily meals would likely be a suitable means of reducing fat, particularly SFA intake in schoolchildren. Cessation of snack intake might also reduce SFA intake, albeit that the effect was not so large.

Fat intake in Japanese adults and children has been increasing steadily ${ }^{(10,21,22)}$. According to the National Health and Nutrition Survey in Japan, mean fat intake in 2003 was $23.1 \mathrm{E} \%$ in adult men and $24.9 \mathrm{E} \%$ in women, but increased to $25.5 \mathrm{E} \%$ and $27.2 \mathrm{E} \%$, respectively, in $2015^{(23)}$. The increase was not as apparent among children (28.4 E\% in 2003 to $29 \cdot 8 \mathrm{E} \%$ in 2015 in boys aged 7-14 years, $29.0 \mathrm{E} \%$ to $29.2 \mathrm{E} \%$ in the same period in girls of the same age) compared with adults, but their absolute intakes of both total fat and SFA were considerably higher than those for adults ${ }^{(10)}$. SFA intake in the Japanese population has been reported in the National Health and Nutrition Survey since 2011. The median SFA intake in 2014 was $19.1 \mathrm{~g} / \mathrm{d}$ in boys aged 7-14 years, $17.8 \mathrm{~g} / \mathrm{d}$ in girls, $14.2 \mathrm{~g} / \mathrm{d}$ in adult men and $12.2 \mathrm{~g} / \mathrm{d}$ in women ${ }^{(10)}$. The change in SFA intake was not clear due to the short period of observation. Higher intake of dairy products among children was reported in the National Health and Nutrition Survey (median intake: $256.0 \mathrm{~g} / \mathrm{d}$ in children aged 7-14 years, $50.0 \mathrm{~g} / \mathrm{d}$ in adults aged $\geq 20$ years), which may be a major reason for the higher fat intake among children $^{(10)}$. Intake of confectioneries was also higher in children (median intake: $20.0 \mathrm{~g} / \mathrm{d}$ in children in the same age range, $0.0 \mathrm{~g} / \mathrm{d}$ in adults) ${ }^{(10)}$. Given the increasing meat intake and decreasing fish intake among the Japanese population $^{(10)}$, SFA intake could increase in the future and careful attention should be paid to it, particularly for children whose SFA intake is already higher than that of adults.

Several studies have reported serum cholesterol levels in Japanese. For adults, one study reported no significant change over the last 10 years $^{(10)}$, whereas another study reported a slight increase in serum total cholesterol from 1990 to $2000^{(24)}$. Among children, no trend was seen in serum total, HDL and non-HDL cholesterol from 1993 to $2008^{(25)}$. Fat intake in Japan is still lower than in Western countries $^{(8,9)}$ and this absolute low intake may be the reason for the non-significant change in serum lipids. On the other hand, mortality from heart disease has been increasing (157 deaths per 100000 population per year in 2015) to become the second-leading cause of death in Japan ${ }^{(12)}$. Although this mortality is lower than 
Table 2 Energy-adjusted, habitual fat intake†, and comparison with Dietary Reference Intakes for Japanese 2015, in Japanese schoolchildren ( $n$ 910) from fourteen elementary and thirteen junior high schools in twelve prefectures of Japan, 2014

\begin{tabular}{|c|c|c|c|c|c|c|c|c|c|c|c|c|c|c|}
\hline \multirow[b]{3}{*}{ Sex } & \multirow{3}{*}{$\begin{array}{l}\text { Habitual } \\
\text { intake }\end{array}$} & \multirow[b]{3}{*}{ Unit } & \multicolumn{4}{|c|}{$\begin{array}{l}\text { Elementary school, } 3 \text { rd grade } \\
\text { (8-9 years; } 154 \text { boys, } 155 \text { girls) }\end{array}$} & \multicolumn{4}{|c|}{$\begin{array}{l}\text { Elementary school, } 5 \text { th grade } \\
\text { (10-11 years; } 144 \text { boys, } 176 \text { girls) }\end{array}$} & \multicolumn{4}{|c|}{$\begin{array}{l}\text { Junior high school, } 2 \text { nd grade } \\
\text { (13-14 years; } 134 \text { boys, } 147 \text { girls) }\end{array}$} \\
\hline & & & \multicolumn{2}{|c|}{ Intake } & \multirow[b]{2}{*}{ Ref. value } & \multirow{2}{*}{$\begin{array}{l}\text { Prevalence (\%) } \\
\text { of inadequacy } \ddagger\end{array}$} & \multicolumn{2}{|c|}{ Intake } & \multirow[b]{2}{*}{ Ref. value } & \multirow{2}{*}{$\begin{array}{l}\text { Prevalence (\%) } \\
\text { of inadequacy }\end{array}$} & \multicolumn{2}{|c|}{ Intake } & \multirow[b]{2}{*}{ Ref. value } & \multirow{2}{*}{$\begin{array}{l}\text { Prevalence (\%) } \\
\text { of inadequacy }\end{array}$} \\
\hline & & & Median & IQR & & & Median & IQR & & & Median & IQR & & \\
\hline \multirow[t]{8}{*}{ Boys } & Fat, total & $\mathrm{g} / \mathrm{d}$ & $60 \cdot 9$ & $56 \cdot 9-63 \cdot 8$ & - & - & $74 \cdot 3$ & $70 \cdot 1-78 \cdot 4$ & - & - & 83.6 & $77 \cdot 9-90 \cdot 3$ & - & - \\
\hline & Fat, total & E\% & $29 \cdot 1$ & $27 \cdot 4-30 \cdot 3$ & 20-30 (DG) & $30.5(30.5)$ & $29 \cdot 6$ & $27 \cdot 8-30 \cdot 9$ & 20-30 (DG) & $42.4(42.4)$ & $28 \cdot 3$ & $26 \cdot 3-30.5$ & 20-30 (DG) & $31.3(30.6)$ \\
\hline & SFA & $g / d$ & $19 \cdot 9$ & $18 \cdot 1-21 \cdot 8$ & - & - & 23.5 & $21 \cdot 8-25 \cdot 3$ & - & - & $26 \cdot 6$ & $23 \cdot 7-29 \cdot 3$ & - & - \\
\hline & SFA & $\mathrm{E} \%$ & 9.5 & $8 \cdot 7-10 \cdot 2$ & $\leq 7(\mathrm{DG}) \S$ & $(100 \cdot 0)$ & 9.3 & $8.6-10.0$ & $\leq 7(\mathrm{DG}) \S$ & $(97.9)$ & 9.0 & $8.0-9.9$ & $\leq 7(\mathrm{DG}) \S$ & $(94.0)$ \\
\hline & MUFA & $g / d$ & 20.4 & $19 \cdot 2-22 \cdot 2$ & - & - & $25 \cdot 5$ & $23 \cdot 4-27 \cdot 6$ & - & - & 29.5 & $27 \cdot 1-32 \cdot 3$ & - & - \\
\hline & PUFA & $\mathrm{g} / \mathrm{d}$ & 11.4 & $10.6-11.9$ & - & - & 13.9 & $13 \cdot 2-14 \cdot 6$ & - & - & $15 \cdot 8$ & $14.4-17.4$ & - & - \\
\hline & $n-6$ PUFA & $\mathrm{g} / \mathrm{d}$ & 9.7 & $9.0-10 \cdot 2$ & $9(\mathrm{Al})$ & - & 11.9 & $11 \cdot 3-12.7$ & $9(\mathrm{Al})$ & - & $13 \cdot 3$ & $12 \cdot 0-14.7$ & $12(\mathrm{Al})$ & - \\
\hline & $n-3$ PUFA & $g / d$ & 1.7 & $1.6-1.8$ & $1.7(\mathrm{Al})$ & - & $2 \cdot 0$ & $1 \cdot 9-2 \cdot 2$ & $1.7(\mathrm{Al})$ & - & 2.5 & $2 \cdot 3-2 \cdot 8$ & $2 \cdot 1(\mathrm{Al})$ & - \\
\hline \multirow[t]{8}{*}{ Girls } & Fat, total & $\mathrm{g} / \mathrm{d}$ & $57 \cdot 6$ & $53 \cdot 6-61 \cdot 6$ & - & - & 69.4 & $63.9-74.7$ & - & - & 78.9 & $74.1-82 \cdot 8$ & - & - \\
\hline & Fat, total & $\mathrm{E} \%$ & 29.9 & $27 \cdot 8-31.9$ & $20-30(\mathrm{DG})$ & $47.7(47.7)$ & $29 \cdot 7$ & $27.5-31.6$ & 20-30 (DG) & $41.5(41.5)$ & 29.8 & $28 \cdot 0-31 \cdot 4$ & 20-30 (DG) & $44.9(44.9)$ \\
\hline & SFA & $\mathrm{g} / \mathrm{d}$ & 18.6 & $17 \cdot 2-20 \cdot 5$ & - & - & 21.9 & $20 \cdot 7-24 \cdot 1$ & - & - & 24.9 & $23 \cdot 5-26 \cdot 3$ & - & - \\
\hline & SFA & E\% & 9.7 & $8 \cdot 9-10 \cdot 6$ & $\leq 7(\mathrm{DG}) \S$ & (99.4) & 9.4 & $8 \cdot 8-10 \cdot 2$ & $\leq 7(\mathrm{DG}) \S$ & (99.4) & 9.4 & $8.9-10 \cdot 0$ & $\leq 7(\mathrm{DG}) \S$ & $(100 \cdot 0)$ \\
\hline & MUFA & $\mathrm{g} / \mathrm{d}$ & $19 \cdot 4$ & $17 \cdot 9-21 \cdot 2$ & - & - & 23.9 & $21 \cdot 7-26 \cdot 0$ & - & - & 27.4 & $25 \cdot 7-29 \cdot 3$ & - & - \\
\hline & PUFA & $\mathrm{g} / \mathrm{d}$ & $10 \cdot 7$ & $9.7-11.4$ & - & - & $12 \cdot 7$ & $11.7-14.0$ & - & - & 14.7 & $13 \cdot 6-15 \cdot 8$ & - & - \\
\hline & $n-6$ PUFA & $\mathrm{g} / \mathrm{d}$ & $9 \cdot 1$ & $8 \cdot 3-9.7$ & $7(\mathrm{Al})$ & - & $10 \cdot 8$ & $9 \cdot 9-12 \cdot 0$ & $8(\mathrm{Al})$ & - & $12 \cdot 4$ & $11 \cdot 3-13.4$ & $10(\mathrm{Al})$ & - \\
\hline & $n-3$ PUFA & $\mathrm{g} / \mathrm{d}$ & 1.6 & $1.5-1.8$ & $1.4(\mathrm{Al})$ & - & 2.0 & $1 \cdot 8-2 \cdot 3$ & $1.5(\mathrm{Al})$ & - & $2 \cdot 3$ & $2 \cdot 2-2 \cdot 5$ & $1.8(\mathrm{Al})$ & - \\
\hline
\end{tabular}

IQR, interquartile range; ref. value, reference value; E\%, percentage of energy; DG, the tentative dietary goal for preventing life-style related diseases; AI, Adequate Intake; EER, estimated energy requirement. All intakes shown here were estimated habitual intakes. Habitual intake was calculated by the best-power method using a three-day diet record.

Nutrient intake of each day was energy-adjusted based on the assumption that every subject consumed the same amount of energy as his/her EER.

fPrevalence of inadequacy is the percentage of children whose energy-adjusted habitual nutrient intake level was outside the range of the corresponding dietary reference intake value. The percentage of subjects whose intake was above the reference range is shown in parentheses.

§Reference value for people aged over 18 years. 
Table 3 Contribution of food groups as SFA sources in Japanese schoolchildren ( $n$ 910) from fourteen elementary and thirteen junior high schools in twelve prefectures of Japan, 2014

\begin{tabular}{|c|c|c|c|c|c|c|c|}
\hline \multirow[b]{3}{*}{ Sex } & \multirow{3}{*}{$\begin{array}{l}\text { Dietary source of SFA } \\
\text { (food group) }\end{array}$} & \multicolumn{6}{|c|}{ Contribution of food group as SFA source† (\%) } \\
\hline & & \multicolumn{2}{|c|}{$\begin{array}{l}\text { Elementary school, } \\
\text { 3rd grade } \\
\text { (8-9 years; } 154 \text { boys, } \\
155 \text { girls) }\end{array}$} & \multicolumn{2}{|c|}{$\begin{array}{c}\text { Elementary school, } \\
\text { 5th grade } \\
\text { (10-11 years; } 144 \text { boys, } \\
176 \text { girls) }\end{array}$} & \multicolumn{2}{|c|}{$\begin{array}{c}\text { Junior high school, } \\
\text { 2nd grade } \\
\text { (13-14 years; } 134 \text { boys, } \\
147 \text { girls) }\end{array}$} \\
\hline & & Mean & SD & Mean & SD & Mean & SD \\
\hline \multirow{13}{*}{ Boys } & Well-milled rice & 1.7 & 0.7 & 1.8 & 0.9 & $2 \cdot 2$ & 1.1 \\
\hline & Bread & 1.8 & 1.8 & $2 \cdot 2$ & 1.9 & 1.8 & 1.7 \\
\hline & Noodles & $2 \cdot 3$ & 4.8 & 1.6 & $3 \cdot 7$ & $2 \cdot 0$ & 4.0 \\
\hline & Pulses & 3.3 & $2 \cdot 6$ & $3 \cdot 3$ & $2 \cdot 6$ & $2 \cdot 9$ & 2.5 \\
\hline & Fish and shellfish & 3.6 & $3 \cdot 7$ & 3.4 & $3 \cdot 7$ & 4.5 & 4.4 \\
\hline & Meat & 23.5 & $11 \cdot 1$ & $27 \cdot 3$ & $10 \cdot 2$ & 30.3 & $12 \cdot 9$ \\
\hline & Eggs & 6.0 & 3.9 & $5 \cdot 9$ & $3 . \overline{7}$ & $5 \cdot 3$ & 3.6 \\
\hline & Dairy products & $27 \cdot 3$ & $10 \cdot 4$ & $25 \cdot 9$ & $9 \cdot 8$ & $24 \cdot 1$ & $10 \cdot 8$ \\
\hline & Fats & 3.8 & $4 \cdot 3$ & 3.9 & 4.4 & 4.4 & $5 \cdot 2$ \\
\hline & Oils & $6 \cdot 7$ & 4.3 & 7.6 & 4.2 & 8.3 & $5 \cdot 7$ \\
\hline & Confectioneries & $13 \cdot 0$ & 10.5 & $10 \cdot 5$ & 8.9 & 8.8 & $9 \cdot 1$ \\
\hline & Seasonings & 3.3 & $3 \cdot 3$ & 3.0 & 3.6 & 1.9 & $2 \cdot 7$ \\
\hline & Ready-made foods & 1.3 & $2 \cdot 3$ & 1.4 & 2.5 & 1.1 & $2 \cdot 1$ \\
\hline \multirow[t]{13}{*}{ Girls } & Well-milled rice & 1.6 & 0.9 & 1.7 & 0.9 & 1.9 & 0.9 \\
\hline & Bread & 1.9 & 1.7 & $2 \cdot 2$ & $2 \cdot 2$ & $2 \cdot 1$ & $2 \cdot 3$ \\
\hline & Noodles & 1.6 & $3 \cdot 1$ & $1 \cdot 7$ & 3.6 & 1.6 & $3 \cdot 3$ \\
\hline & Pulses & 3.1 & $2 \cdot 2$ & 3.0 & 2.5 & 3.3 & $2 \cdot 2$ \\
\hline & Fish and shellfish & 3.6 & 4.0 & 4.0 & 4.8 & 4.2 & 4.3 \\
\hline & Meat & 24.2 & 11.5 & $25 \cdot 1$ & 10.5 & 28.5 & $11 \cdot 7$ \\
\hline & Eggs & 6.4 & 3.9 & $6 \cdot 4$ & 3.5 & $6 \cdot 1$ & 4.0 \\
\hline & Dairy products & $26 \cdot 8$ & 8.7 & $25 \cdot 4$ & $10 \cdot 4$ & 24.3 & 9.3 \\
\hline & Fats & 4.0 & $5 \cdot 2$ & 4.8 & $5 \cdot 8$ & $5 \cdot 3$ & $5 \cdot 8$ \\
\hline & Oils & $7 \cdot 3$ & $4 \cdot 2$ & $7 \cdot 7$ & 5.4 & $7 \cdot 8$ & $6 \cdot 0$ \\
\hline & Confectioneries & 13.5 & $10 \cdot 1$ & 11.6 & $9 \cdot 7$ & 10.1 & $10 \cdot 0$ \\
\hline & Seasonings & $2 \cdot 6$ & $2 \cdot 8$ & $2 \cdot 8$ & $3 \cdot 2$ & 1.7 & $2 \cdot 3$ \\
\hline & Ready-made foods & 1.3 & 3.1 & 1.3 & 2.9 & 0.6 & 1.8 \\
\hline
\end{tabular}

†Contribution (\%) of each food group as a source of SFA to total SFA intake is shown, calculated as: $\{$ [SFA intake (g) from each food group]/[daily total SFA intake $(\mathrm{g})]\} \times 100$. Only mean contributions greater than $1 \%$ are shown.

that in other countries (e.g. 167 deaths per 100000 population per year in the USA in $2014^{(26)} ; 383.4$ deaths (circulatory disease) and 132 deaths (IHD only) per 100000 population per year in the EU in $\left.2013^{(27)}\right)$, careful monitoring of fat intake is important even in Japan to avoid further increases in CVD as a result of excess fat intake.

Since children need additional energy for growth, energy expenditure per kilogram of body weight is higher than in adults ${ }^{(7,11)}$. In particular, the energy cost of growth in infants is high (10-30\% of total energy requirement in those aged $<6$ months) ${ }^{(28)}$ and several dietary guidelines recommend higher fat intake for young children $(<1$ to $<3$ years of age $)^{(6,7,11)}$. Regarding school-aged children, most guidelines recommend almost the same total fat and SFA as those for adults, and reported total fat and SFA intakes in $\mathrm{E} \%$ among school-aged children are in fact the same as in adults in many countries ${ }^{(8,9)}$. However, it seems that evidence to decide the optimum level of SFA intake specific for school-aged children is lacking worldwide, because, strictly speaking, cohort studies with a long follow-up period are needed to show the relationship between SFA intake in childhood and health outcomes in adulthood. Nupponen et al. reported that dietary counselling in childhood to reduce SFA intake was effective in prevention of metabolic syndrome in adolescence $^{(29)}$, but they did not describe the absolute intake of SFA. In accordance with the fact that a number of dietary recommendations apply the recommended SFA intake for adults to children, we applied the DG for SFA in Japanese adults to children. Since dietary habits established in childhood track into later life ${ }^{(13)}$, this application may be the best way to define the recommendation for children at this time. On the other hand, Butte reported that lower fat intake $(<30 \mathrm{E} \%)$ may be associated with inadequate vitamin and mineral intakes and increase the risk of poor growth in children, and that the current recommendation of $30 \mathrm{E} \%$ from dietary fat for children aged $>2$ years is sufficient for adequate growth ${ }^{(28)}$.

Based on our present results, the current status of fat intake in Japanese children is clearly better (i.e. lower) than that of children in many other developed countries. However, the percentage of energy from fat is higher in younger generations, particularly so in Japanese children $^{(10)}$. Given that the trend of increasing total fat and SFA intakes might continue, it may be necessary to discuss whether SFA intake in children should even be restricted in Japan. 


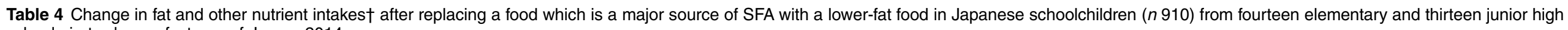
schools in twelve prefectures of Japan, 2014

\begin{tabular}{|c|c|c|c|c|c|c|c|c|c|c|c|c|c|c|c|c|c|c|}
\hline \multirow[b]{3}{*}{ Sex } & \multirow[b]{3}{*}{ Replacement } & \multirow[b]{3}{*}{ Energy or nutrient } & \multirow[b]{3}{*}{ Unit } & \multicolumn{5}{|c|}{$\begin{array}{l}\text { Elementary school, } 3 \text { rd grade } \\
\text { (8-9 years; } 154 \text { boys, } 155 \text { girls) }\end{array}$} & \multicolumn{5}{|c|}{$\begin{array}{c}\text { Elementary school, } 5 \text { th grade } \\
\text { (10-11 years; } 144 \text { boys, } 176 \text { girls) }\end{array}$} & \multicolumn{5}{|c|}{$\begin{array}{l}\text { Junior high school, } 2 \text { nd grade } \\
\text { (13-14 years; } 134 \text { boys, } 147 \text { girls) }\end{array}$} \\
\hline & & & & \multicolumn{2}{|c|}{ Before replacement } & \multicolumn{2}{|c|}{ After replacement } & \multirow[b]{2}{*}{ Diff. } & \multicolumn{2}{|c|}{ Before replacement } & \multicolumn{2}{|c|}{ After replacement } & \multirow[b]{2}{*}{ Diff. } & \multicolumn{2}{|c|}{ Before replacement } & \multicolumn{2}{|c|}{ After replacement } & \multirow[b]{2}{*}{ Diff } \\
\hline & & & & Median & IQR & Median & IQR & & Median & IQR & Median & IQR & & Median & IQR & Median & IQR & \\
\hline \multirow{31}{*}{ Boys } & Full-fat milk & Energy & $\mathrm{kJ} / \mathrm{d}$ & 8075 & 7163-8904 & 7866 & $6996-8657$ & * & 8895 & $8142-10063$ & 8728 & $7975-9740$ & * & 11288 & $9623-12577$ & 11067 & $9427-12226$ & 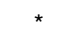 \\
\hline & $\rightarrow$ low- & Energy & $\mathrm{kcal} / \mathrm{d}$ & 1930 & $1712-2128$ & 1880 & $1672-2069$ & * & 2126 & $1946-2405$ & 2086 & $1906-2328$ & * & 2698 & $2300-3006$ & 2645 & & \\
\hline & & Protein & $\mathrm{E} \%$ & 14.6 & $13 \cdot 3-15 \cdot 6$ & $15 \cdot 1$ & $13 \cdot 9-16 \cdot 2$ & * & 14.7 & $13 \cdot 7-15 \cdot 4$ & $15 \cdot 1$ & $14 \cdot 2-16 \cdot 1$ & * & 14.1 & $12 \cdot 7-15 \cdot 0$ & 14.7 & $13 \cdot 1-15 \cdot 5$ & * \\
\hline & & Fat, total & $\mathrm{E} \%$ & $29 \cdot 2$ & $26 \cdot 3-31 \cdot 3$ & 27.0 & $23.9-29.5$ & * & 29.5 & $26 \cdot 7-31 \cdot 8$ & $27 \cdot 4$ & $24 \cdot 7-29 \cdot 6$ & * & $28 \cdot 1$ & $25 \cdot 5-31 \cdot 1$ & $26 \cdot 4$ & $23.5-29.5$ & * \\
\hline & & SFA & $\mathrm{E} \%$ & 9.4 & $8 \cdot 3-10 \cdot 8$ & 7.9 & $6 \cdot 9-9 \cdot 1$ & * & $9 \cdot 2$ & $8 \cdot 3-10 \cdot 3$ & 8.0 & $7 \cdot 2-8 \cdot 9$ & * & 9.0 & $7 \cdot 6-10 \cdot 3$ & 7.7 & $6 \cdot 5-9 \cdot 0$ & * \\
\hline & & Vitamin A & $\mu \mathrm{g} R A E / d$ & 470 & $374-589$ & 415 & $329-527$ & * & 536 & $438-649$ & 477 & $390-592$ & * & 553 & $449-716$ & 501 & $401-654$ & * \\
\hline & & $\begin{array}{l}\mathrm{Ca} \\
\text { Prev inadea for SFAt }\end{array}$ & $\mathrm{mg} / \mathrm{d}$ & 603 & $\begin{aligned} 506-731 \\
94.8\end{aligned}$ & 634 & $\begin{array}{l}543-772 \\
72.7\end{array}$ & * & 641 & $\begin{array}{r}532-776 \\
95.1\end{array}$ & 681 & $\begin{array}{l}566-835 \\
78.5\end{array}$ & * & 700 & $\begin{array}{r}601-878 \\
86.6\end{array}$ & 736 & $\begin{array}{l}645-926 \\
66.4\end{array}$ & * \\
\hline & Full-fat milk & Energy & $\mathrm{kJ} / \mathrm{d}$ & same & as above & 7745 & $6832-8514$ & * & same & $\begin{array}{l}95.1 \\
\text { e as above }\end{array}$ & 8644 & $\begin{array}{l}8.5 \\
7849-9676\end{array}$ & * & same & $\begin{array}{l}86 \cdot 6 \\
\text { as above }\end{array}$ & 10878 & $\begin{array}{l}60.4 \\
9347-12004\end{array}$ & * \\
\hline & $\rightarrow$ skimmed milk & Energy & $\mathrm{kcal} / \mathrm{d}$ & & " and & 1851 & $1633-2035$ & * & & ( & 2066 & $1876-2313$ & * & & (1) & 2600 & 69 & * \\
\hline & & Protein & $\mathrm{E} \%$ & & $"$ & $15 \cdot 1$ & $14 \cdot 0-16 \cdot 3$ & * & & $"$ & $15 \cdot 2$ & $14 \cdot 2-16 \cdot 2$ & * & & " & 14.7 & $13 \cdot 2-15 \cdot 6$ & * \\
\hline & & Fat, total & $\mathrm{E} \%$ & & $"$ & $26 \cdot 3$ & $23 \cdot 3-29 \cdot 0$ & * & & $"$ & 27.0 & $24.1-29.2$ & * & & $"$ & 26.0 & $23.0-29 \cdot 1$ & * \\
\hline & & SFA & $\mathrm{E} \%$ & & $"$ & $7 \cdot 4$ & $6.4-8.5$ & * & & $"$ & 7.6 & $6 \cdot 7-8 \cdot 3$ & * & & $"$ & 7.4 & $6 \cdot 1-8 \cdot 6$ & * \\
\hline & & PUFA & $g / d$ & & $"$ & 11.1 & $8 \cdot 9-13 \cdot 4$ & * & & " & 12.6 & $10 \cdot 7-15.5$ & * & & $"$ & $15 \cdot 1$ & $12 \cdot 4-19 \cdot 6$ & * \\
\hline & & Vitamin A & $\mu \mathrm{g} R A E / d$ & & $"$ & 383 & $298-499$ & * & & $"$ & 449 & & * & & $"$ & 478 & & * \\
\hline & & & $\mathrm{mg} / \mathrm{d}$ & & $"$ & 586 & $486-701$ & * & & $"$ & 622 & $518-756$ & * & & $"$ & 685 & $585-839$ & * \\
\hline & & Prev. inade & $\%$ & & 94.8 & & $60 \cdot 4$ & & & $95 \cdot 1$ & & $68 \cdot 8$ & & & $86 \cdot 6$ & & $55 \cdot 2$ & \\
\hline & & Protein & $\mathrm{E} \%$ & & $"$ & $15 \cdot 1$ & $14 \cdot 0-16 \cdot 4$ & * & & " & 15.5 & $14 \cdot 4-16 \cdot 3$ & * & & " & 14.8 & 13 & * \\
\hline & & Fat, total & $\mathrm{E} \%$ & & $"$ & 26.8 & 24.4 & * & & $"$ & 26.6 & & * & & $"$ & $25 \cdot 2$ & & * \\
\hline & & SFA & $\mathrm{E} \%$ & & " & 8.6 & $7.5-9.8$ & * & & $"$ & 8.3 & $7 \cdot 2-9.4$ & * & & " & 7.9 & $6.7-9.1$ & * \\
\hline & & PU & $\mathrm{g} / \mathrm{d}$ & & $"$ & 10.8 & $8 \cdot 8-12 \cdot 8$ & * & & $"$ & 12.2 & $10 \cdot 1-14.7$ & * & & $"$ & 14.5 & $11.9-18.6$ & * \\
\hline & & Thiamin & $\mathrm{mg} / \mathrm{d}$ & 1.0 & $0.8-1.2$ & 1.0 & $0.8-1.2$ & * & $1 \cdot 1$ & $1.0-1.4$ & 1.2 & $1.0-1.4$ & * & 1.3 & 1.1 & 1.4 & $1 \cdot 1-1 \cdot 7$ & * \\
\hline & & & $\mathrm{mg} / \mathrm{d}$ & 6.8 & $5.9-7.7$ & $7 \cdot 1$ & $6.0-8.0$ & * & 7.6 & $6 \cdot 6-8 \cdot 7$ & 8.0 & $6 \cdot 9-9 \cdot 1$ & * & 8.6 & $7 \cdot 5-9.9$ & 9.0 & $7 \cdot 8-10.6$ & * \\
\hline & & nadeq. for SFA & $\%$ & & 94.8 & & 87.7 & & & 95.1 & & 81.9 & & & 86.6 & & $68 \cdot 7$ & \\
\hline & Confectioneries & Energy & $\mathrm{kJ} / \mathrm{d}$ & same & as above & 7627 & $6786-8351$ & * & same & e as above & 8544 & $7803-9523$ & 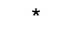 & same & as above & 10715 & $9218-11765$ & * \\
\hline & $\rightarrow$ del & Energy & $\mathrm{kcal} / \mathrm{d}$ & & & 1823 & $1622-1996$ & * & & $"$ & 2042 & $1865-2276$ & * & & $"$ & 2561 & 2203-2812 & * \\
\hline & & Protei & $\mathrm{E} \%$ & & $"$ & $15 \cdot 1$ & $13 \cdot 9-16 \cdot 0$ & * & & " & $15 \cdot 0$ & $14 \cdot 1-15 \cdot 9$ & * & & $"$ & 14.6 & $13.1-15.5$ & * \\
\hline & & Fat, total & $\mathrm{E} \%$ & & $"$ & 28.5 & $25 \cdot 2-30 \cdot 9$ & * & & $"$ & 28.8 & $26 \cdot 4-31.6$ & * & & $"$ & 27.8 & $24.9-31 \cdot 3$ & * \\
\hline & & SFA & $\mathrm{E} \%$ & & $"$ & 8.9 & $8 \cdot 1-10 \cdot 4$ & * & & $"$ & $9 \cdot 1$ & $8 \cdot 1-10 \cdot 1$ & * & & $"$ & 8.8 & $7 \cdot 4-9.9$ & * \\
\hline & & PUFA & $\mathrm{g} / \mathrm{d}$ & & $"$ & 10.3 & $8 \cdot 8-12 \cdot 7$ & * & & $"$ & $12 \cdot 2$ & $10 \cdot 3-15 \cdot 1$ & * & & $"$ & 14.8 & $11.9-18.0$ & * \\
\hline & & Carbohydrate & $\mathrm{E} \%$ & $55 \cdot 3$ & $52 \cdot 2-58 \cdot 7$ & 55.3 & $52 \cdot 2-58.7$ & & $54 \cdot 6$ & $51 \cdot 9-57 \cdot 7$ & 54.6 & $51.8-57.6$ & & $56 \cdot 1$ & $52 \cdot 1-59 \cdot 1$ & 56.0 & $51.7-59.2$ & \\
\hline & & $\begin{array}{l}\text { Salt } \\
\text { Prev inadea for SFAt }\end{array}$ & $\mathrm{g} / \mathrm{d}$ & $9 \cdot 1$ & $94 \cdot 8^{7 \cdot 3-10 \cdot 6}$ & 8.9 & $92.9^{7 \cdot 1-10 \cdot 4}$ & * & 9.9 & $\begin{array}{l}8.2-11.5 \\
95 \cdot 1\end{array}$ & 9.6 & $93 \cdot 8^{8 \cdot 1-11 \cdot 4}$ & * & 11.0 & $\begin{array}{l}9 \cdot 6-13 \cdot 0 \\
86 \cdot 6\end{array}$ & $10 \cdot 8$ & $\begin{array}{l}9 \cdot 4-12 \cdot 6 \\
82.8\end{array}$ & * \\
\hline
\end{tabular}


Table 4 Continued

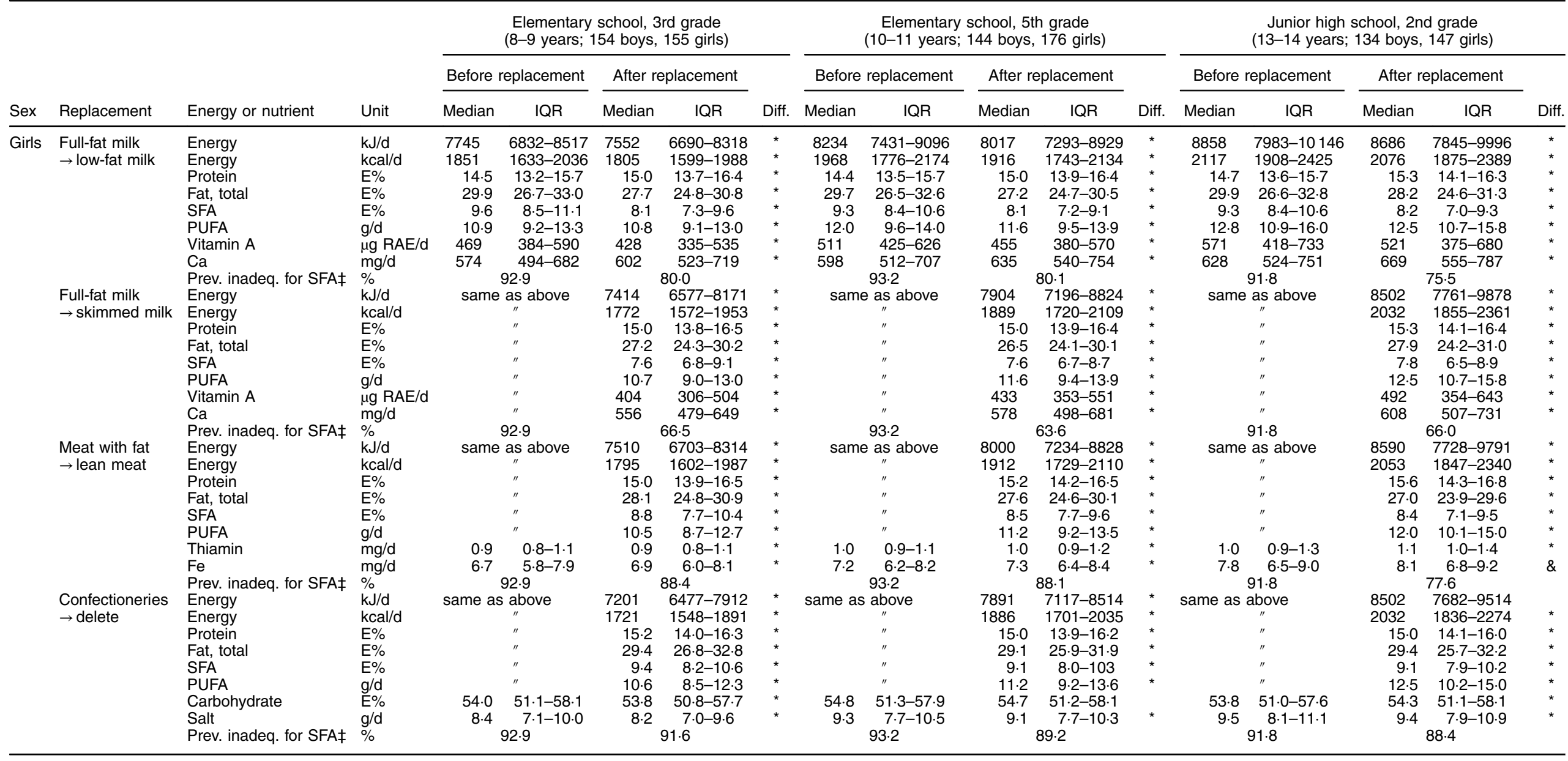

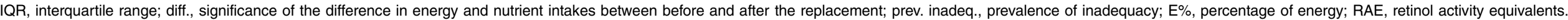
${ }^{\star} P<0.05$ (significant difference, Wilcoxon signed-rank test).

†Mean energy and nutrient intakes in three days are shown without energy adjustment.

łPrevalence of inadequacy for SFA is the percentage of children whose mean SFA intake level was outside the range of the dietary reference intake value for SFA in adults ( $\leq 7 \mathrm{E} \%$ ). 
We previously reported that the major dietary problem of Japanese schoolchildren was the intake of excess salt, excess fat and low dietary fibre ${ }^{(14)}$. Regarding fat, intakes of meat, dairy products and confectioneries are good targets for intervention to reduce fat, particularly SFA intake. These foods have also been reported as major dietary sources of SFA and cholesterol in other countries ${ }^{(6,7)}$. For example, Rehm et al. reported that substituting skimmed or low-fat milk for whole, reduced-fat and flavoured milk reduced the percentage of energy from SFA by $2.5 \mathrm{E} \%$ and $1.4 \mathrm{E} \%$, respectively, in the USA ${ }^{(30)}$. In Japan, whole milk is provided in school lunches. Inadequacy of $\mathrm{Ca}$ intake was much lower on a school day than on a non-school day (34.0\% v. $74.3 \%$ in boys, $31 \cdot 6 \% v \cdot 78.2 \%$ in girls) as reported in our previous study ${ }^{(14)}$, and this is a beneficial effect of milk in school lunches. However, it may be necessary to discuss the fat content in milk to reduce SFA intake among Japanese children. The substitution of meat with fat may be more complex, but was attempted in the Dietary Intervention Study in Children (DISC) study ${ }^{(31)}$. In the present study, cessation of confectionery intake was not so effective in reducing fat, particularly SFA intake; intake was low, at approximately $20 \mathrm{~g} / 4184 \mathrm{~kJ}$ (1000 kcal), and a number of children did not have the habit of snacking (data not shown). Thus, cessation of snacking can only be useful in those who habitually consume confectioneries. In Japanese children, the contribution of dairy products as a source of SFA decreased with age, whereas that of meat increased with age, suggesting that age-specific interventions may be effective in reducing fat intake. Sex differences were less obvious than those of age, but the contribution of meat as an SFA source was slightly larger in boys and that of confectioneries was larger in girls.

The present study has several strengths, which reflect those in our previous paper ${ }^{(14)}$. The study was schoolbased and nationwide, with a relatively high participation rate $(76.9 \%)$. The study areas were chosen from various prefectures of different characteristics and the selected schools were public ones without special food or health education. The generalizability of the results is considered to be sufficient. Additional strengths were its quantitative assessment of dietary intake and use of a three-day DR, which allowed us to estimate the habitual intake and dietary sources of each nutrient in the analysed population.

At the same time, several limitations also warrant mention. First, since most analyses were performed with stratification by sex and age, the number of children in each stratum was approximately 150. Although this might appear small for estimation of average intakes and exact distributions, results across strata were similar, and could be interpreted. Second, a three-day DR might be too short to allow habitual intake to be estimated with precision. However, given the heavy burden of DR assessment on participants, a period longer than $3 \mathrm{~d}$ was not considered feasible. Third, as nutrient content is not uniform even in the same kind of food (e.g. full-fat milk or meat with fat), changes in fat and nutrient intakes before and after food replacement may be inconstant. We used representative nutrition contents in the food composition table $e^{(15)}$ and these must have provided the best estimations compared with other simulation methods.

\section{Conclusions}

Since one-third to nearly one-half of our Japanese schoolchildren consumed excess fat and SFA intake in almost all of them was greater than the DG value ( $\leq 7 \mathrm{E} \%)$ for Japanese adults, careful monitoring of fat intake in the Japanese population should be continued. The major dietary sources of SFA were meat, dairy products and confectioneries. Adoption of low-fat milk and/or lean meat in daily meals might be a suitable means of reducing the intake of fat, particularly SFA, in Japanese schoolchildren.

\section{Acknowledgements}

Acknowledgements: The authors thank the dietitians, school nurses and teachers who supported this research in each school, and the staff of the municipal government in each study area for their valuable contribution. Financial support: This work was supported by a Health and Labour Sciences Research Grant (number H26-Jyunkankitou (seisaku)-shitei-001) from the Ministry of Health, Labour and Welfare, Japan. The Ministry of Health, Labour and Welfare, Japan had no role in the design, analysis or writing of this article. Conflict of interest: None. Authorship: S.S. designed and directed the study. K.A. supported field establishment and recruitment for the study. S.S. and K.A. supported the collection of dietary data. K.A. performed the statistical analyses and drafted the paper. Both authors contributed to the development of the submitted manuscript. Ethics of buman subject participation: This study was conducted in accordance with the guidelines laid down in the Declaration of Helsinki and all procedures involving human subjects were approved by the Ethics Committee of the University of Tokyo, Faculty of Medicine (approval number 10653, approval date 3 October 2014). Participants (children) and their guardians were informed about the study verbally and by a written document before answering the questionnaire, and responding to the questionnaire was regarded as consent for study participation. Since no personally identifiable information such as name or mailing address was collected, all collected data were anonymous.

\section{References}

1. Mensink RP \& Katan MB (1992) Effect of dietary fatty acids on serum lipids and lipoproteins. A meta-analysis of 27 trials. Arterioscler Thromb 12, 911-919. 
2. Clarke R, Frost C, Collins R et al. (1997) Dietary lipids and blood cholesterol: quantitative meta-analysis of metabolic ward studies. BMJ 314, 112-117.

3. Hegsted DM, Ausman LM, Johnson JA et al. (1993) Dietary fat and serum lipids: an evaluation of the experimental data. Am J Clin Nutr 57, 875-883.

4. Yamagishi K, Iso H, Kokubo Y et al. (2013) Dietary intake of saturated fatty acids and incident stroke and coronary heart disease in Japanese communities: the JPHC Study. Eur Heart J 34, 1225-1232.

5. Mozaffarian D, Micha R \& Wallace S (2010) Effects on coronary heart disease of increasing polyunsaturated fat in place of saturated fat: a systematic review and meta-analysis of randomized controlled trials. PLoS Med 7, e1000252.

6. EFSA Panel on Dietetic Products, Nutrition, and Allergies (2010) Scientific Opinion on Dietary Reference Values for fats, including saturated fatty acids, polyunsaturated fatty acids, monounsaturated fatty acids, trans fatty acids, and cholesterol. EFSA J 8, 1461.

7. Institute of Medicine, Food and Nutrition Board (2005) Dietary Reference Intakes for Energy, Carbohydrate, Fiber, Fat, Fatty Acids, Cholesterol, Protein, And Amino Acids. Washington, DC: National Academy Press.

8. Harika RK, Eilander A, Alssema M et al. (2013) Intake of fatty acids in general populations worldwide does not meet dietary recommendations to prevent coronary heart disease: a systematic review of data from 40 countries. Ann Nutr Metab 63, 229-238.

9. Harika RK, Cosgrove MC, Osendarp SJ et al. (2011) Fatty acid intakes of children and adolescents are not in line with the dietary intake recommendations for future cardiovascular health: a systematic review of dietary intake data from thirty countries. Br J Nutr 106, 307-316.

10. Cancer Control and Health Promotion Division, Health Service Bureau, Ministry of Health Labour and Welfare, Japan (2014) The National Health and Nutrition Survey in Japan (in Japanese). http://www.mhlw.go.jp/bunya/ kenkou/eiyou/h26-houkoku.html (accessed April 2017).

11. Ministry of Health, Labour and Welfare (2014) Dietary Reference Intakes for Japanese, 2015. Tokyo: Daiichi Shippan Publishing Co., Ltd.

12. Statistics and Information Department, Minister's Secretariat, Ministry of Health, Labour and Welfare, Japan (2015) Vital Statistics: Trends in leading causes of death. http://www. mhlw.go.jp/english/database/db-hw/populate/dl/03.pdf (accessed April 2017).

13. Mikkila V, Rasanen L, Raitakari OT et al. (2005) Consistent dietary patterns identified from childhood to adulthood: the cardiovascular risk in Young Finns Study. Br J Nutr $\mathbf{9 3}$, 923-931.

14. Asakura K \& Sasaki S (2017) School lunches in Japan: their contribution to healthier nutrient intake among elementaryschool and junior high-school children. Public Health Nutr 20, 1523-1533.

15. The Council for Science and Technology (2010) Standard Tables of Food Composition in Japan, Fifth Revised and Enlarged Edition - 2010. Tokyo: Official Gazette Co-operation.

16. Ikiuo (Sawamura) K, Hashimoto R \& Murata M (2010) Discussion on the new physical fitness definition in school health program - on the comparison between a new and a previous definition for the physical fitness of school aged children and the secular trend of the prevalence of obesity and thinness in them from 1980 to 2006. J Child Health 69 , 6-13.

17. Dodd KW, Guenther PM, Freedman LS et al. (2006) Statistical methods for estimating usual intake of nutrients and foods: a review of the theory. J Am Diet Assoc 106, $1640-1650$.

18. Nusser SM, Carriquiry AL, Dodd KW et al. (1996) A semiparametric transformation approach to estimating usual daily intake distributions. J Am Stat Assoc 91, 1440-1449.

19. Yokoyama $\mathrm{T}$ (2013) Theory and application of statistical methods to estimate the distribution of usual intakes of a nutrient in a population: for the appropriate use of dietary reference intakes (in Japanese). Jpn J Nutr Diet 7, Suppl. 1, S7-S14.

20. Asakura K, Uechi K, Masayasu S et al. (2016) Sodium sources in the Japanese diet: difference between generations and sexes. Public Health Nutr 19, 2011-2023.

21. Yoshiike N, Matsumura Y, Yamaguchi M et al. (1998) Trends of average intake of macronutrients in 47 prefectures of Japan from 1975 to 1994 - possible factors that may bias the trend data. J Epidemiol 8, 160-167.

22. Murata M (2000) Secular trends in growth and changes in eating patterns of Japanese children. Am J Clin Nutr $\mathbf{7 2}$, 5 Suppl., 1379S-1383S.

23. Cancer Control and Health Promotion Division, Health Service Bureau, Ministry of Health Labour and Welfare, Japan (2015) The summary of results of the National Health and Nutrition Survey in Japan, 2015. (in Japanese). http:// www.mhlw.go.jp/file/04-Houdouhappyou-10904750Kenkoukyoku-Gantaisakukenkouzoushinka/kekkagaiyou. pdf (accessed April 2017).

24. Arai H, Yamamoto A, Matsuzawa Y et al. (2005) Serum lipid survey and its recent trend in the general Japanese population in 2000. $J$ Atheroscler Thromb 12, 98-106.

25. Kouda K, Nakamura H, Nishio N et al. (2010) Trends in body mass index, blood pressure, and serum lipids in Japanese children: Iwata population-based annual screening (1993-2008). J Epidemiol 20, 212-218.

26. National Center for Health Statistics (2015) Health, United States, 2015: With Special Feature on Racial and Ethnic Health Disparities. Washington, DC: US Government Printing Office.

27. Eurostat (2013) Statistics Explained: Causes of death statistics. http://ec.europa.eu/eurostat/statistics-explained/index. php/Causes_of_death_statistics (accessed April 2017).

28. Butte NF (2000) Fat intake of children in relation to energy requirements. Am J Clin Nutr 72, 5 Suppl., 1246S-1252S.

29. Nupponen M, Pahkala K, Juonala M et al. (2015) Metabolic syndrome from adolescence to early adulthood: effect of infancy-onset dietary counseling of low saturated fat: the Special Turku Coronary Risk Factor Intervention Project (STRIP). Circulation 131, 605-613.

30. Rehm CD, Drewnowski A \& Monsivais P (2015) Potential population-level nutritional impact of replacing whole and reduced-fat milk with low-fat and skim milk among US children aged 2-19 years. J Nutr Educ Behav 47, 61-68.e1.

31. Van Horn L, Obarzanek E, Friedman LA et al. (2005) Children's adaptations to a fat-reduced diet: the Dietary Intervention Study in Children (DISC). Pediatrics 115, $1723-1733$. 